\title{
Future perspectives on cell therapy for autism spectrum disorder
}

\author{
MAKOTO NABETANI ${ }^{1, *}$; TAKEO MUKAI ${ }^{2}$ \\ ${ }^{1}$ Department of Pediatrics, Yodogawa Christian Hospital, Osaka, 533-0024, Japan \\ 2 Department of Cell Processing and Transfusion, The Institute of Medical Science, The University of Tokyo, Tokyo, 108-8639, Japan
}

Key words: Autism, ASD, Cell therapy, Umbilical cord blood cells, MSC, Mesenchymal stromal cells

\begin{abstract}
Autism spectrum disorder (ASD) is a complex neurodevelopmental condition characterized by impairments in social communication, abnormal to absent verbal communication, the presence of repetitive stereotypic verbal and nonverbal behaviors and restricted interests, with onset early in life. We showed cognitive and behavioral characteristics of ASD by impairment of communication, cognition, perception, motor skills, executive function, theory of mind and emotion control. Recently, pathogenesis of immune pathology in the brains of individuals with ASD has been focused. New therapeutic approaches in the viewpoints of immune modulation and microglial function are logical for novel treatments for individuals with ASD. Cell therapies such as umbilical cord blood cells and mesenchymal stromal cells for ASD will be a challenging and encouraging field in the future clinical study with progress of biotechnological science.
\end{abstract}

$\begin{array}{ll}\text { Abbreviations } \\ \text { ASD: } & \text { Autism spectrum disorder } \\ \text { MSCs: } & \text { mesenchymal stromal cells } \\ \text { UCBs: } & \text { umbilical cord blood cells } \\ \text { EVs: } & \text { extracellular vesicles } \\ \text { HGF: } & \text { hepatocyte growth factor } \\ \text { GDNF: } & \text { glial cell line-derived neurotrophic factor } \\ \text { VEGF: } & \text { vascular endothelial growth factor } \\ \text { HIE: } & \text { hypoxic-ischemic-encephalopathy } \\ \text { CP: } & \text { cerebral palsy } \\ \text { IL-6: } & \text { interleukin } 6 \\ \text { TNF-a: } & \text { tumor necrosis factor-alpha } \\ \text { BDNF: } & \text { brain derived neurotrophic factor } \\ \text { LPS: } & \text { lipopolysaccharide } \\ \text { GTPase: } & \text { guanosine triphosphatase }\end{array}$

\section{Introduction}

Autism spectrum disorder (ASD) is a complex neurodevelopmental condition characterized by impairment in social communication, verbal communication, the presence of repetitive stereotypic verbal and non-verbal behavior and restricted interests, with an onset early in life. Prevalence of ASD has been increasing in the last two decades. In Japan, the prevalence of individuals with intellectual disabilities needing special educational

\footnotetext{
*Address correspondence to: Makoto Nabetani, a103111@ych.or.jp Received: 02 July 2021; Accepted: 27 August 2021
}

program in school, including those with ASD, increased more than threefold from 21,000 in 2002 to 74,000 in 2013, similar to findings in the other countries (Ministry of Education, Culture, Sports, Science and Technology-Japan, 2013; Blumberg et al., 2013; Guthrie et al., 2019).

\section{Cognitive and Behavioral Characteristics of ASD Due to Various Factors}

The main cognitive and behavioral characteristics of ASD are impairment of communication, cognition, perception, motor skills, executive function, theory of mind and emotion control (Gabrielsen et al., 2018; Robertson and BaronCohen, 2017; Mottron et al., 2006; Ketcheson et al., 2017; Demetriou et al., 2018; Jones et al., 2018; Haney et al., 2018; Conner et al., 2019; Baron-Cohen et al., 1985) (Fig. 1) and various behavioral therapies based on neurophysiological viewpoints have been considered the foremost strategies for management of individuals on ASD (Sharma et al., 2018b). Yet, there is currently no apparent effective therapy for ASD (Tachibana et al., 2017).

Genetic factors (Sullivan and Geschwind, 2019; Ruzzo et al., 2019; Parikshak et al., 2018), chronic inflammation, impairment of the microglia, oxidative stress, hormones/neurotransmitters abnormality (Gao and Penzes, 2015; Volk et al., 2015) and environmental factors (Oudin et al., 2019; Rossignol et al., 2014) are likely contributing to the development of ASD, however the precise pathophysiology is unknown.

More recently, pathogenesis of immune pathology in the brain of individuals with ASD has been a focus of research. 


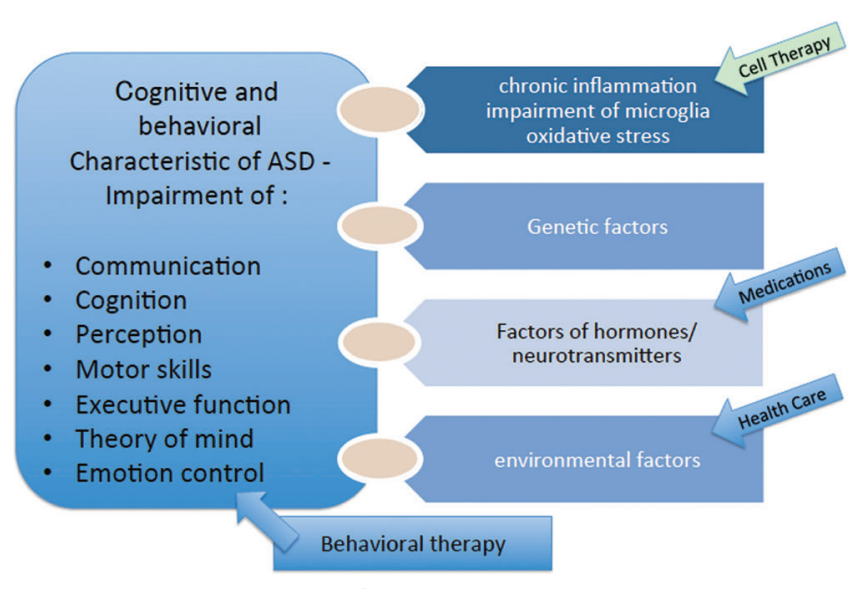

FIGURE 1. New strategy of ASD treatment.

Voineagu et al. (2011) reported over expression of immunerelated gene networks (Voineagu et al., 2011), Braunschweig et al. (2013) reported the presence of maternal antibodies in fetal brain tissue (Braunschweig et al., 2013), Vargas et al. (2005) described atypical levels of pro-inflammatory cytokines (IL-6, TNF-a) in cerebrospinal fluid (CSF) of patients, and further reports suggested that excessive microglial activation leads to aberrant neural connections (Morgan et al., 2010; Suzuki et al., 2013).

From the recent basic research, abnormal activation of microglia by activation of TLR4 signaling pathway following maternal Lipopolysaccharide exposure, which in turn was involved in excessive synaptic pruning to decrease synaptic plasticity in the offspring may be one of the reasons for the autism-like behavior in the offspring mice (Xiao et al., 2021). On the other hand, early postnatal allergic airway inflammation has been reported to induce dystrophic microglia that exhibit defective synaptic pruning upon short- and long-term allergen exposure resulting in excitatory postsynaptic surplus and ASD-like behavior (Saitoh et al., 2021). These basic research suggest abnormal microglial activation which is responsible for synaptic pruning partially contributes to ASD pathology. These resulted in a novel therapeutic approach for an immunomodulation or repair of microglial function. Preclinical and clinical studies have shown that umbilical cord blood contains hematopoietic stem cells, endothelial progenitor cells, and mesenchymal stromal cells (MSCs) that, through paracrine signaling, alter brain connectivity and modulate inflammation (Meier et al., 2006; Sun et al., 2017). Infusion of autologous cord blood cells (UCBs) have been shown to be safe in individuals with cerebral palsy (CP), ASD, and other acquired brain injuries. Dawson et al. reported safe and feasible autologous UCBs infusions in young children with ASD and several promising outcomes were published (Dawson et al., 2017; Dawson and Fletcher-Watson, 2021; Dawson et al., 2020; Li et al., 2015). Recently, MSCs for individuals with ASD had favorable outcomes (Lv et al., 2013; Riordan et al., 2019; Sun et al., 2020) (Table 1).

Recent clinical trials in ASD were done by BM-MNC $(\mathrm{n}=3), \mathrm{UCB}(\mathrm{n}=2)$, UC-MSC $(\mathrm{n}=2)$ and UCB + UC-MSC $(\mathrm{n}=1)$. Frequency of administration are 1 times $(\mathrm{n}=4), 2$ times $(\mathrm{n}=1), 3$ times $(\mathrm{n}=2)$ or 4 times $(\mathrm{n}=1)$.
Number of cells of administration are various (each dose $1 \times$ $10^{6}-5 \times 10^{7}$ cells $/ \mathrm{kg}$ ). UCB and UC-MSC are performed mainly using IV, while BMMNC is performed using IT. IV injection is easier compared to IT, and UC-MSC and UCB are distributed to the central nervous system without being trapped in the lung and blood-brain-barrier. UC-MSCs therapy for ASD is performed considering neurotrophic effects of UC-MSCs in addition to immunomodulation against chronic inflammation. Few serious adverse events were observed after transplantation. Autologous BM-MNC transplantation is required in order to avoid transplant rejection, but the procedure to take $\mathrm{BM}-\mathrm{MNC}$ might be harmful and administration of BM-MNC intrathecal injection in ASD could be harmful. On the other hand, most reports suggest that UC-MSCs has a therapeutic potential with relative safety and allogeneic MSCs can be ordered as a most suitable critical timing.

\section{UCBs for individuals with ASD}

UCBs deliver a protective effect from impairment of microglia, chronic inflammation and oxidative stress, as well as enhance neurological regeneration. Human CD34 positive cells have been shown to secrete various growth factors such as brain derived neurotrophic factor (BDNF), glial cell linederived neurotrophic factor (GDNF), vascular endothelial growth factor (VEGF), and numerous angiogenic factors, including hepatocyte growth factor (HGF) and insulin-like growth factor-1 (Yoshihara et al., 2008; Majka et al., 2001). Considering that human CD34 cells have an effect on BDNF production and knowing that this neurotrophic factor is widely described as altered in ASD, this mechanism could be a potential therapeutic effect of UCBs" (SantosTerra et al., 2021; Kern et al., 2013; Saghazadeh and Rezaei, 2017). Marchezan et al. (2018) reported that immunological and microglial changes are related to behavioral outcomes and that immunological and microglial changes in the TEA, as well as a behavioral improvement after managing these changes (Marchezan et al., 2018).

Considering the angiogenic and vascular reparative capabilities of endothelial progenitor cells, there is an altered expression of genes associated with blood brain barrier integrity coupled with increased neuroinflammation and possibly impaired gut barrier integrity in the ASD brain (Fiorentino et al., 2016). In 2004, Taguchi et al. (2004) reported that endothelial progenitor cells have angiogenic and vascular reparative capabilities that make them ideal for neurovascular repair (Taguchi et al., 2004). With a rich vascular environment, along with the generation of other nurturing neuronal mediators from CD34 positive cells, such as VEGF, epidermal growth factor 2, and insulin-like growth factor 1, endothelial progenitor cells enhance subsequent neuronal regeneration (Nakatomi et al., 2002). Some reports suggest that UCBs could suppress chronic inflammation in addition to paracrine and angiogenesis (Shahaduzzaman et al., 2013). Impairment of microglia has been shown to have profound effect on neural development, possibly resulting in ASD (Takano, 2015). Therefore, modulation of the phenotype of the microglia may be a novel therapeutic strategy for the treatment of neurological disorders accompanied by inflammation. Li et al. (2016) 
TABLE 1

Recent clinical review of cell therapy for Autism Spectrum Disorder

\begin{tabular}{|c|c|c|c|c|c|c|c|}
\hline & Source & Number & $\begin{array}{l}\text { Age } \\
\text { (range) }\end{array}$ & $\begin{array}{l}\text { Route of } \\
\text { administration }\end{array}$ & Number of cells & Results & Severe adverse events \\
\hline $\begin{array}{l}\text { Sharma et al. } \\
\text { (2012) }\end{array}$ & BM-MNC & 1 & 8 & IT & $1 \times 10^{6} / \mathrm{kg}$ & Improvement & No \\
\hline $\begin{array}{l}\text { Nguyen } \\
\text { Thanh et al. } \\
\text { (2021) }\end{array}$ & BM-MNC & 30 & $3-7$ & IT & $\begin{array}{l}1 \text { st: } 4.2 \times 10^{67} / \mathrm{kg} \\
2 \text { nd: } 4.1 \times 10^{7} / \mathrm{kg}\end{array}$ & $\begin{array}{l}\text { Significantly Improvement } \\
\text { in the Childhood Autism } \\
\text { Rating Scale (CARS), and } \\
\text { the median Vineland } \\
\text { Adaptive Behavior Scales }\end{array}$ & No \\
\hline $\begin{array}{l}\text { Lv et al. } \\
\text { (2013) }\end{array}$ & $\begin{array}{l}\text { UCB/UC- } \\
\mathrm{MSC}\end{array}$ & 37 & $3-12$ & IV/IT + IV & $\begin{array}{l}\text { UCB: } 2 \times 10^{6} / \mathrm{kg} \\
\text { UC-MSC: } 1 \times \\
10^{6} / \mathrm{kg}\end{array}$ & $\begin{array}{l}\text { Improvement in the } \\
\text { Childhood Autism Rating } \\
\text { Scale (CARS), Clinical } \\
\text { Global Impression (CGI) } \\
\text { scale and Aberrant } \\
\text { Behavior Checklist (ABC) }\end{array}$ & No \\
\hline $\begin{array}{l}\text { Li et al. } \\
\text { (2015) }\end{array}$ & UCB & 14 & $3-12$ & IV/IT & $2-6 \times 10^{6}$ cells & $\begin{array}{l}\text { Improvement in the } \\
\text { Childhood autism rating } \\
\text { scale (CARS) and increase } \\
\text { of NGF levels in the CSF }\end{array}$ & No \\
\hline $\begin{array}{l}\text { Dawson et al. } \\
\text { (2017) }\end{array}$ & UCB & 25 & $\begin{array}{l}2.26- \\
5.97\end{array}$ & IV & $1-5 \times 10^{7}$ cells & $\begin{array}{l}\text { Significant improvements } \\
\text { in children's behavior }\end{array}$ & No \\
\hline $\begin{array}{l}\text { Riordan et al. } \\
(2019)\end{array}$ & UC-MSC & 20 & $6-16$ & IV & $\begin{array}{l}3.6 \times 10^{7} \text { cells } \\
\times 4\end{array}$ & $\begin{array}{l}\text { The CARS and ATEC } \\
\text { scores of eight subjects } \\
\text { decreased }\end{array}$ & No \\
\hline $\begin{array}{l}\text { Sun et al. } \\
(2020)\end{array}$ & UC-MSC & 12 & $4-9$ & IV & $2 \times 106 / \mathrm{kg} \times 3$ & $\begin{array}{l}6 / 12 \text { participants } \\
\text { demonstrated } \\
\text { improvement in at least } \\
\text { two ASD-specific } \\
\text { measures }\end{array}$ & $\begin{array}{l}5 \text { participants developed } \\
\text { new class I anti-human } \\
\text { leukocyte antigen (HLA) } \\
\text { antibodies }\end{array}$ \\
\hline $\begin{array}{l}\text { Sharma et al. } \\
(2020)\end{array}$ & BM-MNC & 254 & $\begin{array}{l}\text { Under } 5 \\
\text {-over } 15\end{array}$ & IT & $\begin{array}{l}1 \text { time } \\
\text { immediately } \\
\text { after isolateon }\end{array}$ & $\begin{array}{l}\text { Improvement of eye } \\
\text { contact, attention and } \\
\text { concentration, } \\
\text { hyperactivity, sitting } \\
\text { tolerance, social } \\
\text { interaction, stereotypical } \\
\text { behavior, aggressiveness, } \\
\text { communication, speech, } \\
\text { command following and } \\
\text { self-stimulatory behavior }\end{array}$ & No \\
\hline
\end{tabular}

Note: UCB = umbilical cord blood; IT = intrathecal; IV = intravenous.

reported that UCBs administration at $12 \mathrm{~h}$ after hypoxicischemic event reduces white matter injury by affecting activated microglia (Li et al., 2016).

In terms of glucose metabolism in ASD, Mitelman et al. (2018) reported that glucose metabolic rates were decreased in the parietal lobe, frontal premotor and eye-fields areas, and amygdala. Anil Kumar et al. (2017) reported that 4 out of the 10 patients with autism had abnormal PET scan findings, while none of the patients in the control group had abnormal PET scan. Findings of their study support the view of hypometabolism of glucose in subjects with ASD (Anil Kumar et al., 2017). Sharma et al. (2018a) reported that $[18 \mathrm{~F}]$ 2-fluoro-2-deoxy-D-glucose PET scan was performed on 45 patients with ASD to study age-related developmental changes in the brain metabolism. Results showed that, in contrary to control data, the median standardized uptake values in patients with ASD decrease linearly with increase in age. As compared to controls, autism children below 5 years showed greater metabolism and older children showed lower metabolism. In ASD group, comparison of absolute standardized uptake values within different regions of the brain revealed relatively lower metabolism in amygdala, hippocampus, parahippocampal gyrus, caudate nucleus, cerebellum, mesial temporal lobe, thalamus, superior and middle temporal pole, and higher metabolic uptake in calcarine fissure and Heschl's gyrus. These results help in understanding the baseline metabolism and developmental changes of brain metabolism among different age groups in ASD (Sharma et al., 2018a). Zhao et al. (2020) reported that characterized changes on glucose 
metabolism, and also ASD-like behaviors in 1st and 2nd generations from 12- and 18-month-old male mice, respectively. Whole Genome Bisulfite Sequencing of sperm from advanced paternal age mice identified differentially methylated regions within the whole genome, and differentially methylated regions within promoter regions, suggesting that specific genes and relevant pathways might be associated with ASD and aberrant glucose metabolism in the offspring from advanced paternal age males. These results strongly suggest that epigenetic reprogramming induced by aging in male sperm may lead to high risks of aberrant glucose metabolism and the development of ASD behaviors in intergenerational and transgenerational offspring (Zhao et al., 2020). UCBs and peripheral blood mononuclear cells infusion therapy for patients with CP improved brain glucose metabolism by PET study (Min et al., 2013; Rah et al., 2017). Autologous bone marrow mononuclear cells therapies for patients with ASD also showed improvement of glucose metabolism and various cognitive and behavioral symptoms such as eye contact, attention and concentration, hyperactivity, sitting tolerance, social interaction, stereotypical behavior, aggressiveness, communication, speech, command following and selfstimulatory behavior as well as improvement of glucose metabolism and motor function in patients with $\mathrm{CP}$ (Sharma et al., 2015; Sharma et al., 2020). In 2020, KikuchiTaura et al. (2020) reported that angiogenesis is activated by bone marrow mononuclear cells via gap junction-mediated cell-cell interaction and that cell-cell interaction via gap junction is the prominent pathway for activation of angiogenesis at endothelial cells and improvement of glucose uptake. Transplanted BM-MNCs transferred small molecules to endothelial cells via gap junction followed by activated Hif- $1 \alpha$ and suppressed autophagy at endothelial cells (Kikuchi-Taura et al., 2020). The mechanism of UCBs to improve glucose metabolism might lead to therapeutic potential for individuals with ASD.

\section{MSCs for individuals with ASD}

Sanagi et al. (2019) reported that microglia in patients and animals with ASD symptoms could frequently be in the apoptotic phase with high turnover rates of microglia found in some pathological conditions (Sanagi et al., 2019). MSCs have been reported to secrete heterogeneous lipid bilayer vesicles called extracellular vesicles (EVs), which act as mediators for inter-cell communication. These exosomes/EVs secreted from MSCs are known to improve neuronal function in neurologically injured models (Fuloria et al., 2021). Perets et al. (2020) reported long term beneficial effect of neurotrophic factors-secreting MSCs transplantation in the autism mouse model (Perets et al., 2020). Hadar et al. (2016) reported that transplantation of MSC resulted in a reduction of stereotypical behaviors, a decrease in cognitive rigidity and an improvement in social behavior. Tissue analysis revealed elevated BDNF protein levels in the hippocampus accompanied by increased hippocampal neurogenesis in the MSC-transplanted mice compared with sham treated mice. This result might indicate a possible mechanism underpinning the behavioral improvement (Segal-Gavish et al., 2016). Perets et al. (2017) reported that exosomes derived from MSC would have a direct beneficial effect on the behavioral autistic-like phenotype of the genetically modified Shank3B KO mouse model of ASD. They indicated that intranasal treatment with exosomes derived from MSC improves the core ASD-like deficits of this mouse model of ASD and therefore has the potential to treat ASD patients carrying the Shank3 mutation (Perets et al., 2017). Our group also demonstrated the amelioration of neuronal injury followed by functional improvement in MSCadministered mice models, which resulted from the secretion of trophic factors such as BDNF and HGF rather than neuronal differentiation and eternal cell replacement by MSCs (Mukai et al., 2017; 2018). Human CD34 positive cells have been shown to secrete various growth factors such as BDNF, GDNF, VEGF, and numerous angiogenic factors, including HGF and insulin-like growth factor-1.

We also demonstrated that secretomes from MSCs can change the phenotype of activated microglia. Umbilical cord derived MSCs immunomodulated microglia and changed the phenotype of LPS-activated microglia restoring actin dynamics and phagocytosis by increasing active Rho GTPase, in which microglia changed their amoeboid to a more ramified pattern (Mukai et al., 2021). This suppression and immunomodulation of activated microglia by MSCs may lead to therapeutic potential for individuals with ASD in which excessive microglial activation lead to aberrant neural connections. On the other hand, human UC-MSC therapies for individuals with $\mathrm{CP}$ showed improvement of motor function and much increase of glucose metabolism by PET-CT scan (Gu et al., 2020). The mechanism of MSCs to improve glucose metabolism might lead to therapeutic potential for individuals with ASD.

\section{Future perspectives}

Immune modulation and microglial function repair may serve as novel therapies for individuals with ASD and other neurological diseases. Multiple mechanisms of paracrine, angiogenesis, immunomodulation, glucose metabolism and repair of microglial function by cell therapies might lead to clinical therapeutic potential for individuals with ASD. These cell therapies for patients with ASD have been often directed at children who cannot consent clearly. We should consider cell therapy clinical trials in patients with ASD, once the ethical and diagnostic barriers can be resolved.

\section{New strategy of ASD treatment}

The main cognitive and behavioral characteristics of ASD are impairment of communication, cognition, perception, motor skills, executive function, theory of mind and emotion control. And various behavioral therapies based on neurophysiological viewpoints have been considered the foremost strategies for management of individuals on the Autism spectrum. Genetic factors, chronic inflammation, impairment of the microglia, oxidative stress, hormones/ neurotransmitters abnormality and environmental factors are likely contributing to the development of ASD. These strategies such as behavioral therapies, medications to hormones/neurotransmitters abnormality and health care to prevent environmental factors show no apparent effectiveness for ASD. Cell therapies in the viewpoints of immune 
modulation and microglial function could be new strategies of ASD treatments.

Acknowledgement: The authors thank Prof. Ran D. Goldman from the University of British Columbia for his valuable advice.

Author Contribution: The authors confirm contribution to the paper as follows: study conception and design: MN Author; data collection: TM Author; analysis and interpretation of results: TM Author; draft manuscript preparation: MN Author. All authors reviewed the results and approved the final version of the manuscript.

Funding Statement: We have no fund support regarding this study.

Conflicts of Interest: We have no conflict of interest to disclose regarding this study.

\section{References}

Anil Kumar BN, Malhotra S, Bhattacharya A, Grover S, Batra YK (2017). Regional cerebral glucose metabolism and its association with phenotype and cognitive functioning in patients with Autism. Indian Journal of Psychological Medicine 39: 262-270. DOI 10.4103/0253-7176.207344.

Baron-Cohen S, Leslie AM, Frith U (1985). Does the autistic child have a "theory of mind"? Cognition 21: 37-46. DOI 10.1016/0010-0277(85)90022-8.

Blumberg SJ, Bramlett MD, Kogan MD, Schieve LA, Jones JR et al. (2013). Changes in prevalence of parent-reported autism spectrum disorder in school-aged U.S. children: 2007 to 2011-2012. National Health Statistics Reports, 1-11.

Braunschweig D, Krakowiak P, Duncanson P, Boyce R, Hansen RL et al. (2013). Autism-specific maternal autoantibodies recognize critical proteins in developing brain. Translational Psychiatry 3: e277. DOI 10.1038/tp.2013.50.

Conner CM, White SW, Beck KB, Golt J, Smith IC et al. (2019). Improving emotion regulation ability in autism: The Emotional Awareness and Skills Enhancement (EASE) program. Autism 23: 1273-1287. DOI 10.1177/1362361318810709.

Dawson G, Sun JM, Baker J, Carpenter K, Compton S et al. (2020). A phase II randomized clinical trial of the safety and efficacy of intravenous umbilical cord blood infusion for treatment of children with autism spectrum disorder. Journal of Pediatrics 222: 164-73.e5. DOI 10.1016/j.jpeds.2020.03.011.

Dawson G, Sun JM, Davlantis KS, Murias M, Franz L et al. (2017). Autologous cord blood infusions are safe and feasible in young children with autism spectrum disorder: Results of a singlecenter phase I open-label trial. Stem Cells Translational Medicine 6: 1332-1339. DOI 10.1002/sctm.16-0474.

Dawson M, Fletcher-Watson S (2021). Commentary: What conflicts of interest tell us about autism intervention research-A commentary on Bottema-Beutel et al. 2020. Journal of Child Psychology and Psychiatry 62: 16-18. DOI 10.1111/jcpp.13315.

Demetriou EA, Song CY, Park SH, Pepper KL, Naismith SL et al. (2018). Autism, Early Psychosis, and Social Anxiety Disorder: A transdiagnostic examination of executive function cognitive circuitry and contribution to disability. Translational Psychiatry 8: 1606. DOI 10.1038/s41398-018-0193-8.

Fiorentino M, Sapone A, Senger S, Camhi SS, Kadzielski SM et al. (2016). Blood-brain barrier and intestinal epithelial barrier alterations in autism spectrum disorders. Molecular Autism 7: 597. DOI 10.1186/s13229-016-0110-z.

Fuloria S, Subramaniyan V, Dahiya R, Dahiya S, Sudhakar K et al. (2021). Mesenchymal stem cell-derived extracellular vesicles: Regenerative potential and challenges'. Biology 10: 172.

Gabrielsen TP, Anderson JS, Stephenson KG, Beck J, King JB et al. (2018). Functional MRI connectivity of children with autism and low verbal and cognitive performance. Molecular Autism 9: 145. DOI 10.1186/s13229-018-0248-y.

Gao R, Penzes P (2015). Common mechanisms of excitatory and inhibitory imbalance in schizophrenia and autism spectrum disorders. Current Molecular Medicine 15: 146-167. DOI 10.2174/1566524015666150303003028.

Gu J, Huang L, Zhang C, Wang Y, Zhang R et al. (2020). Therapeutic evidence of umbilical cord-derived mesenchymal stem cell transplantation for cerebral palsy: A randomized, controlled trial. Stem Cell Research \& Therapy 11: 1240. DOI 10.1186/ s13287-019-1545-x.

Guthrie W, Wallis K, Bennett A, Brooks E, Dudley J et al. (2019). Accuracy of autism screening in a large pediatric network. Pediatrics 144: e20183963. DOI 10.1542/peds.2018-3963.

Hadar SG, Golan K, Noy B, Ran B, Javier G, Liat E, Israel A, Daniel O, Tali K (2016). Mesenchymal stem cell transplantation promotes neurogenesis and ameliorates autism related behaviors in BTBR mice. Autism Research 9: 17-32.

Haney JL, Houser L, Cullen JA (2018). Parental perceptions and child emotional and behavioral problems in Autism. Journal of Autism and Developmental Disorders 48: 12-27. DOI 10.1007/s10803-017-3288-9.

Jones CRG, Simonoff E, Baird G, Pickles A, Marsden AJS et al. (2018). The association between theory of mind, executive function, and the symptoms of autism spectrum disorder. Autism Research 11: 95-109. DOI 10.1002/aur.1873.

Kern JK, Geier DA, Sykes LK, Geier MR (2013). Evidence of neurodegeneration in autism spectrum disorder. Translational Neurodegeneration 2: 193. DOI 10.1186/2047-9158-2-17.

Ketcheson L, Hauck J, Ulrich D (2017). The effects of an early motor skill intervention on motor skills, levels of physical activity, and socialization in young children with autism spectrum disorder: A pilot study. Autism 21: 481-492. DOI 10.1177/ 1362361316650611.

Kikuchi-Taura A, Okinaka Y, Takeuchi Y, Ogawa Y, Maeda M et al. (2020). Bone marrow mononuclear cells activate angiogenesis via gap junction-mediated cell-cell interaction. Stroke 51: 1279-1289. DOI 10.1161/STROKEAHA.119.028072.

Li J, Yawno T, Sutherland A, Loose J, Nitsos I et al. (2016). Preterm white matter brain injury is prevented by early administration of umbilical cord blood cells. Experimental Neurology 283: 179-187. DOI 10.1016/j.expneurol.2016.06.017.

Li Q, Chen CF, Wang DY, Lü YT, Huan Y et al. (2015). Transplantation of umbilical cord blood mononuclear cells increases levels of nerve growth factor in the cerebrospinal fluid of patients with autism. Genetics and Molecular Research 14: 8725-8732. DOI 10.4238/2015.July.31.21.

Lv YT, Zhang Y, Liu M, Qiuwaxi JN, Ashwood P et al. (2013). Transplantation of human cord blood mononuclear cells and umbilical cord-derived mesenchymal stem cells in autism. Journal of Translational Medicine 11: 2127. DOI 10.1186/1479-5876-11-196.

Majka M, Janowska-Wieczorek A, Ratajczak J, Ehrenman K, Pietrzkowski Z et al. (2001). Numerous growth factors, cytokines, and chemokines are secreted by human CD34(+) cells, myeloblasts, erythroblasts, and megakaryoblasts and 
regulate normal hematopoiesis in an autocrine/paracrine manner. Blood 97: 3075-3085. DOI 10.1182/blood.V97.10.3075.

Marchezan J, Winkler Dos Santos EGA, Deckmann I, Riesgo RDS (2019). Immunological dysfunction in autism spectrum disorder: A potential target for therapy. Neuroimmunomodulation 25: 300319. DOI 10.1159/000492225.

Meier C, Middelanis J, Wasielewski B, Neuhoff S, Roth-Haerer A et al. (2006). Spastic paresis after perinatal brain damage in rats is reduced by human cord blood mononuclear cells. Pediatric Research 59: 244-249. DOI 10.1203/01. pdr.0000197309.08852.f5.

Min K, Song J, Kang JY, Ko J, Ryu JS et al. (2013). Umbilical cord blood therapy potentiated with erythropoietin for children with cerebral palsy: A double-blind, randomized, placebocontrolled trial. Stem Cells 31: 581-591. DOI 10.1002/ stem.1304.

Ministry of Education, Culture, Sports, Science and TechnologyJapan (2013). Materials on how educational support should be after school-Data collection.

Mitelman SA, Bralet MC, Haznedar MMehmet, Hollander E, Shihabuddin L et al. (2018). Positron emission tomography assessment of cerebral glucose metabolic rates in autism spectrum disorder and schizophrenia. Brain Imaging and Behavior 12: 532-546. DOI 10.1007/s11682-017-9721-z.

Morgan JT, Chana G, Pardo CA, Achim C, Semendeferi K et al. (2010). Microglial activation and increased microglial density observed in the dorsolateral prefrontal cortex in autism. Biological Psychiatry 68: 368-376. DOI 10.1016/j. biopsych.2010.05.024.

Mottron L, Dawson M, Soulières I, Hubert B, Burack J (2006). Enhanced perceptual functioning in autism: An update, and eight principles of autistic perception. Journal of Autism and Developmental Disorders 36: 27-43. DOI 10.1007/s10803-005-0040-7.

Mukai T, Martino EDi, Tsuji S, Blomgren K, Nagamura-Inoue T et al. (2021). Umbilical cord-derived mesenchymal stromal cells immunomodulate and restore actin dynamics and phagocytosis of LPS-activated microglia via PI3K/Akt/Rho GTPase pathway. Cell Death Discovery 7: 1314.

Mukai T, Mori Y, Shimazu T, Takahashi A, Tsunoda H et al. (2017). Intravenous injection of umbilical cord-derived mesenchymal stromal cells attenuates reactive gliosis and hypomyelination in a neonatal intraventricular hemorrhage model. Neuroscience 355: 175-187. DOI 10.1016/j.neuroscience.2017.05.006.

Mukai T, Tojo A, Nagamura-Inoue T (2018). Umbilical cord-derived mesenchymal stromal cells contribute to neuroprotection in neonatal cortical neurons damaged by oxygen-glucose deprivation'. Frontiers in Neurology 9: 281. DOI 10.3389/ fneur.2018.00466.

Nakatomi H, Kuriu T, Okabe S, Yamamoto S, Hatano O et al. (2002). Regeneration of hippocampal pyramidal neurons after ischemic brain injury by recruitment of endogenous neural progenitors. Cell 110: 429-441. DOI 10.1016/S0092-8674(02)00862-0.

Nguyen Thanh L, Nguyen HP, Ngo MD, Bui VA, Dam PTM, Bui HTP, Ngo DV, Tran KT, Dang TTT, Duong BD, Nguyen PAT, Forsyth N, Heke M (2021). 'Outcomes of bone marrow mononuclear cell transplantation combined with interventional education for autism spectrum disorder'. Stem Cells Translational Medicine 10: 14-26.

Oudin A, Frondelius K, Haglund N, Källén K, Forsberg B et al. (2019). Prenatal exposure to air pollution as a potential risk factor for autism and ADHD. Environment International 133: 105149. DOI 10.1016/j.envint.2019.105149.
Parikshak NN, Swarup V, Belgard TG, Irimia M, Ramaswami G et al. (2018). Author Correction: Genome-wide changes in lncRNA, splicing, and regional gene expression patterns in autism. Nature 560: E30. DOI 10.1038/s41586-018-0295-8.

Perets N, Oron O, Herman S, Elliott E, Offen D (2020). Exosomes derived from mesenchymal stem cells improved core symptoms of genetically modified mouse model of autism Shank3B. Molecular Autism 11: 409.

Perets N, Segal-Gavish H, Gothelf Y, Barzilay R, Barhum Y et al. (2017). Long term beneficial effect of neurotrophic factorssecreting mesenchymal stem cells transplantation in the BTBR mouse model of autism. Behavioural Brain Research 331: 254-260. DOI 10.1016/j.bbr.2017.03.047.

Rah WJ, Lee YH, Moon JH, Jun HJ, Kang HR et al. (2017). Neuroregenerative potential of intravenous G-CSF and autologous peripheral blood stem cells in children with cerebral palsy: A randomized, double-blind, cross-over study. Journal of Translational Medicine 15: 304. DOI 10.1186/s12967-017-1120-0.

Riordan NH, Hincapié ML, Morales I, Fernández G, Allen N et al. (2019). Allogeneic human umbilical cord mesenchymal stem cells for the treatment of autism spectrum disorder in children: Safety profile and effect on cytokine levels. Stem Cells Translational Medicine 8: 1008-1016. DOI 10.1002/ sctm.19-0010.

Robertson CE, Baron-Cohen S (2017). Sensory perception in autism. Nature Reviews Neuroscience 18: 671-684. DOI 10.1038/ nrn.2017.112.

Rossignol DA, Genuis SJ, Frye RE (2014). Environmental toxicants and autism spectrum disorders: A systematic review. Translational Psychiatry 4: e360. DOI 10.1038/tp.2014.4.

Ruzzo EK, Pérez-Cano L, Jung JY, Wang LK, Kashef-Haghighi D et al. (2019). Inherited and de novo genetic risk for autism impacts shared networks. Cell 178: 850-866.e26. DOI 10.1016/j.cell.2019.07.015.

Saghazadeh A, Rezaei N (2017). Brain-derived neurotrophic factor levels in autism: A systematic review and meta-analysis. Journal of Autism and Developmental Disorders 47: 10181029. DOI 10.1007/s10803-016-3024-x.

Saitoh BY, Tanaka E, Yamamoto N, Kruining DV, Iinuma K et al. (2021). Early postnatal allergic airway inflammation induces dystrophic microglia leading to excitatory postsynaptic surplus and autism-like behavior. Brain Behavior \& Immunity 95: 362-380. DOI 10.1016/j.bbi.2021.04.008.

Sanagi T, Sasaki T, Nakagaki K, Minamimoto T, Kohsaka $S$ et al. (2019). Segmented Iba1-positive processes of microglia in autism model marmosets. Frontiers in Cellular Neuroscience 13: 151. DOI 10.3389/fncel.2019.00344.

Santos-Terra J, Deckmann I, Schwingel GBrum, Vinicius Contri Paz A, Gama CS et al. (2021). Resveratrol prevents long-term structural hippocampal alterations and modulates interneuron organization in an animal model of ASD. Brain Research 147593.

Segal-Gavish H, Karvat G, Barak N, Barzilay R, Ganz J et al. (2016). Mesenchymal stem cell transplantation promotes neurogenesis and ameliorates autism related behaviors in BTBR mice. Autism Research 9: 17-32. DOI 10.1002/aur.1530.

Shahaduzzaman M, Golden JE, Green S, Gronda AE, Adrien E et al. (2013). A single administration of human umbilical cord blood $\mathrm{T}$ cells produces long-lasting effects in the aging hippocampus. Age 35: 2071-2087. DOI 10.1007/s11357-012-9496-5.

Sharma A, Gokulchandran N, Chopra G, Kulkarni P, Lohia M, Badhe P, Jacob VC (2012). Administration of autologous bone 
marrow-derived mononuclear cells in children with incurable neurological disorders and injury is safe and improves their quality of life. Cell Transplant 21: S79-S90.

Sharma A, Gokulchandran N, Sane H, Nivins S, Paranjape A, Badhe P (2018a). The baseline pattern and age-related developmental metabolic changes in the brain of children with autism as measured on positron emission tomography/computed tomography scan. World Journal of Nuclear Medicine 17: 94-101.

Sharma AK, Gokulchandran N, Kulkarni PP, Sane HM, Sharma R et al. (2020). Cell transplantation as a novel therapeutic strategy for autism spectrum disorders: A clinical study. Americal Journal of Stem Cells 9: 89-100.

Sharma A, Sane H, Gokulchandran N, Kulkarni P, Gandhi S et al. (2015). A clinical study of autologous bone marrow mononuclear cells for cerebral palsy patients: A new frontier. Stem Cells International 2015: 1-11. DOI 10.1155/ 2015/905874.

Sharma SR, Gonda X, Tarazi FI (2018b). Autism Spectrum Disorder: Classification, diagnosis and therapy. Pharmacology and Therapeutics 190: 91-104. DOI 10.1016/j.pharmthera.2018.05.007.

Sullivan PF, Geschwind DH (2019). Defining the genetic, genomic, cellular, and diagnostic architectures of psychiatric disorders. Cell 177: 162-183. DOI 10.1016/j.cell.2019.01.015.

Sun JM, Dawson G, Franz L, Howard J, McLaughlin C et al. (2020). Infusion of human umbilical cord tissue mesenchymal stromal cells in children with autism spectrum disorder. Stem Cells Translational Medicine 9: 1137-1146. DOI 10.1002/sctm.19-0434.

Sun JM, Song AW, Case LE, Mikati MA, Gustafson KE et al. (2017). Effect of autologous cord blood infusion on motor function and brain connectivity in young children with cerebral palsy: A randomized, placebo-controlled trial. Stem Cells Translational Medicine 6: 2071-2078. DOI 10.1002/ sctm.17-0102.

Suzuki K, Sugihara G, Ouchi Y, Nakamura K, Futatsubashi M et al. (2013). Microglial activation in young adults with autism spectrum disorder. JAMA Psychiatry 70: 49-58. DOI 10.1001/jamapsychiatry.2013.272.
Tachibana Y, Miyazaki C, Ota E, Mori R, Hwang Y et al. (2017). A systematic review and meta-analysis of comprehensive interventions for pre-school children with autism spectrum disorder (ASD). PLoS One 12: e0186502. DOI 10.1371/ journal.pone.0186502.

Taguchi A, Soma T, Tanaka H, Kanda T, Nishimura H et al. (2004). Administration of $\mathrm{CD}_{3}{ }^{+}$cells after stroke enhances neurogenesis via angiogenesis in a mouse model. Journal of Clinical Investigation 114: 330-338. DOI 10.1172/ JCI200420622.

Takano T (2015). Role of microglia in autism: Recent advances. Developmental Neuroscience 37: 195-202. DOI 10.1159/ 000398791.

Vargas DL, Nascimbene C, Krishnan C, Zimmerman AW, Pardo CA (2005). Neuroglial activation and neuroinflammation in the brain of patients with autism. Annals of Neurology 57: 6781. DOI 10.1002/(ISSN)1531-8249.

Voineagu I, Wang X, Johnston P, Lowe JK, Tian Y et al. (2011). Transcriptomic analysis of autistic brain reveals convergent molecular pathology. Nature 474: 380-384. DOI 10.1038/ nature10110.

Volk L, Chiu SL, Sharma K, Huganir RL (2015). Glutamate synapses in human cognitive disorders. Annual Review of Neuroscience 38: 127-149. DOI 10.1146/annurev-neuro-071714-033821.

Xiao L, Yan J, Feng D, Ye S, Yang T et al. (2021). Critical role of TLR4 on the microglia activation induced by maternal LPS exposure leading to ASD-like behavior of offspring. Frontiers in Cell and Developmental Biology 9: 99. DOI 10.3389/fcell.2021.634837.

Yoshihara T, Taguchi A, Matsuyama T, Shimizu Y, Kikuchi-Taura A et al. (2008). Increase in circulating CD34-positive cells in patients with angiographic evidence of moyamoya-like vessels. Journal of Cerebral Blood Flow \& Metabolism 28: 1086-1089. DOI 10.1038/jcbfm.2008.1.

Zhao WL, Gu NH, Li ZZ, Wang GS, Cheng CY, Sun F (2020). Autism-like behaviors and abnormality of glucose metabolism in offspring derived from aging males with epigenetically modified sperm. Aging 12: 19766-19784. DOI 10.18632/aging.104061. 